\section{Remembering the legacy of Fred Kavli}

F red Kavli, the founder and chairman of The Kavli Foundation, passed away in his home in Santa Barbara, Calif., on November 21, 2013, at the age of 86 .

A philanthropist, physicist, entrepreneur, business leader, and innovator, Kavli established The Kavli Foundation in 2000 to advance science for the benefit of humanity. Based in Southern California, the Foundation today includes an international community of basic research institutes in the fields of astrophysics, nanoscience, neuroscience, and theoretical physics. Located on three continents, the institutes are home to some of the most renowned researchers in their fields, according to Jim Cohen, the Kavli Foundation's Director of Communications.

The Foundation has also established and supported an international program of conferences, symposia, endowed professorships, and other activities. This includes being a founding partner of the biennial Kavli Prizes, which recognize scientists for their seminal advances in three research areas: astrophysics, nanoscience, and neuroscience.

Kavli founded the Kavlico Corporation in 1958, which made millions by becoming one of the world's largest suppliers of sensors for appliances, automobiles, and aircraft. He remained $\mathrm{CEO}$ and sole shareholder of the company until it was sold in 2000 , the same year he established the Foundation. He began donating much of his fortune to science, establishing the Kavli Prize, which he intended to rival the Nobel Prize.

Among the seven winners of the Kavli Prizes in 2012 was, in nanoscience, Mildred S. Dresselhaus, a professor at the Massachusetts Institute

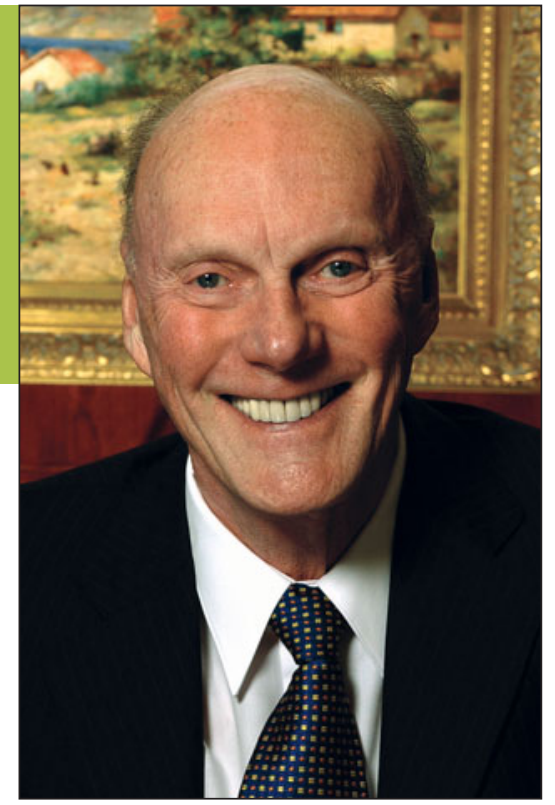

of Technology, whose research helped usher in the age of nanotechnology.

"His greatest contribution to science was setting up a foundation incorporating his wisdom and money. He was personally involved with the concept and execution, but not in choosing winners," said Dresselhaus. "He was very interested in the concept of individuals with means giving back to society in some forms that make a difference to the future of human existence and also to increase understanding of our universe from the biggest to the smallest."

Dresselhaus recalled a time in 2012 when she was traveling from Oslo to Bergen by train, and there on the same second-class car was Fred Kavli. "I was very surprised to see such a prominent businessman on the second-class car and not on a first-class car, and later asked him why he was not on the first-class car. His response was immediate. $\mathrm{He}$ explained that in life one has to be frugal and spend available money to buy things that make a difference. To him, contributing to advancing science was more important than making a marginal improvement in his personal comfort."

The 17 Kavli Institutes-scattered from Beijing to Berkeley_have each received at least $\$ 7.5$ million from the Foundation. The money serves as an endowment that returns about $\$ 400,000$ per year toward research. The Founda- tion plans to expand the contribution to each institute to about $\$ 10$ million.

"Fred's contribution to the advancement of science is remarkable and far-reaching, and I am certain future generations will owe him a great debt of gratitude for the discoveries that he encouraged and facilitated," said Joanna Aizenberg, Director of the Kavli Institute for Bionano Science and Technology (KIBST). "Through the Foundation's generous support of KIBST at Harvard University, we have been able to explore problems that we would never have had an opportunity to explore otherwise. In particular, we have pursued earlystage, high-risk, high-reward research that addresses fundamental questions around the behavior of biomaterials at the nanoscale level. The Institute brings together theorists and experimentalists, as well as clinicians, across a wide range of interdisciplinary areas."

"Fred Kavli was a man with great curiosity, he liked to discover things," said A. Paul Alivisatos, Director of the Kavli Energy NanoSciences Institute at Berkeley. "He was an inventor and an entrepreneur with a deep belief in the power of new ideas to change the world. He brought his adventuresome and entrepreneurial spirit to his philanthropic venture, where he rapidly established the Kavli Foundation as a global force in support of fundamental science. His choice of areas of science to sponsor (the very large in astrophysics, the very small in nanoscience, and the very complex in neuroscience, and the foundational area of theoretical physics) was inspired."

The Kavli Foundation established the Fred Kavli Distinguished Lectureship in Nanoscience and chose the MRS Fall Meeting in 2007 as the venue for the first lecture. For several years to follow, this distinct honor has been presented at MRS Meetings and continues to support scientific research, honor scientific achievement, and promote public understanding of scientists and their work.

Science will benefit from Fred Kavli's enthusiasm, generosity, and zest for discoveries for years to come.

Lori A. Wilson 